\title{
O-mesityl(sulfonyl)hydroxylamine: A Novel Reagent for Reduction of Electron Deficient $\alpha, \beta$-Unsaturated Carbonyl Derivatives
}

\author{
Gondi Sudershan Reddy, ${ }^{1 *}$ \\ ${ }^{1}$ Departments of Chemistry, National Taiwan Normal University, Taipei, Taiwan, 116 (ROC). \\ Correspondence email: gondisr@gmail.com
}

Abstract: Hydrogenation of electron deficient $\alpha, \beta$-unsaturated carbonyl derivatives using O-mesityl(sulfonyl)hydroxylamine in the presence of catalytic amount of ytterbium triflate to obtain good to excellent is described.

Key words: O-mesityl(sulfonyl)hydroxylamine (MSA), $\alpha, \beta$-unsaturated carbonyl, Hydrogenation, $\mathrm{Yb}(\mathrm{OTf}) 3$, selectivity.

Introduction: Selective hydrogenation of olefin bond of conjugated carbonyl compounds in the presence of other function groups is an important task in organic synthesis. As hydrogen ${ }^{1,2}$ from gas cylinder is potentially explosive and requires to be used with caution in a special apparatus, search for alternative methods to conventional hydrogenation procedures such as heterogeneous and homogeneous catalytic transfer hydrogenation is still going on. Surprisingly, there are only a few methods available in the literature for effecting the reduction of the olefin in $\alpha, \beta$-unsaturated carbonyl/nitro molecules. The most common used reagents for the reduction of conjugated carbonyl compounds are palladium assisted hydrogen transfer by ammonium formate, ${ }^{3}$ formic acid, ${ }^{4}$ Diphenyl sulfide,${ }^{5}$ polystyrene, ${ }^{6}$ or potassium formate,${ }^{7}$ Palladium acetate,${ }^{8}$ metal catalyzed reduction by sodium hydrogen telluride, ${ }^{9}$ copper nanoparticles, ${ }^{10}$ samarium iodide, ${ }^{11}$ lithium aluminum hydride with $\mathrm{SbCl}_{3},{ }^{12}$ sodium boroacetate, ${ }^{13}$ sodium borohydride reduced hydroxy ester, ${ }^{14}$ nickel chloride, ${ }^{15,16}$ iridium, ${ }^{17}$ ruthenium, ${ }^{18}$ silane hydride ${ }^{19}$ and Yeast in organic solvent system. ${ }^{20}$

Recently, O-mesityl(sulfonyl)hydroxylamine is used for aziridination of simple olefins. ${ }^{21}$ It is a versatile class of reagents and has been used for the various functional group transformation, migration of O-Phenylhydroxylamine, ${ }^{22} \quad \mathrm{~N}$-Unsubstituted Arylsulfilimines, ${ }^{23}$ Hydroxy-amine, ${ }^{24}$ Hydrazine, ${ }^{25}$ and Beckman Rearrangement. ${ }^{26}$ Surprisingly, no significant effort has yet been made to utilize this potential reagent for the regio and stereoselective hydrogenation of double bonds of $\alpha, \beta$-unsaturated 
compounds. In the course of research programme directed towards the synthesis of novel reagent for hydrogenation of olefins. We found a new and convenient entry to a hydrogenation method. Herein we disclose that O-mesityl(sulfonyl)hydroxylamine (MSA), is a very efficient reagent in the selective hydrogenation of olefin conjugated to carbonyl group without effecting other functional groups in the molecule. Thus, treatment of camphor pyrazolidinone derived acrylate $1 \mathrm{a}$ with $O$ mesityl(sulfonyl)hydroxylamine in $\mathrm{CH}_{2} \mathrm{Cl}_{2}$ provided $2 \mathrm{a}$ in $70 \%$ material yield (Table 1 entry 7). The structure was initially assigned by ${ }^{1} \mathrm{H},{ }^{13} \mathrm{C}-\mathrm{NMR}$ and HRMS analyses and further confirmed by single crystal X-ray analysis.

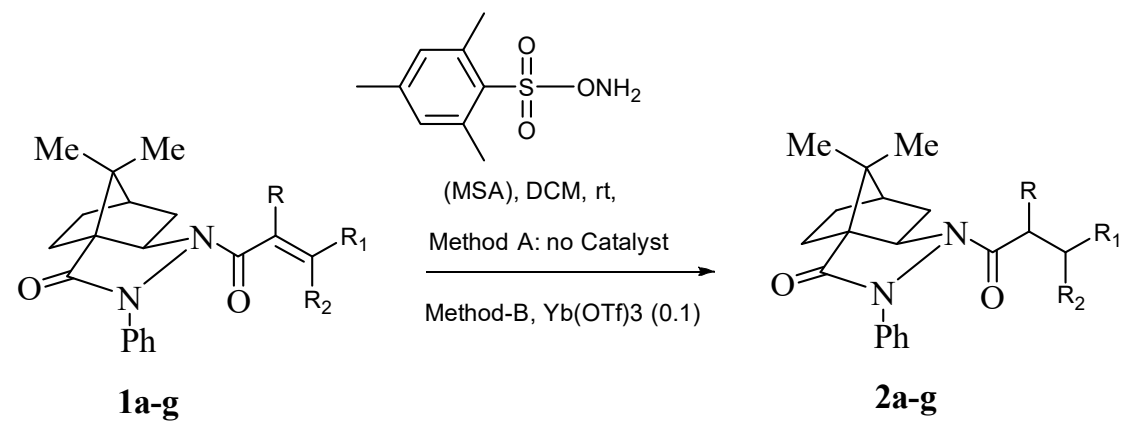

\begin{tabular}{|l|c|l|l|l|l|c|c|c|}
\hline entry & Substrate & $\mathbf{R}=$ & $\mathbf{R}_{\mathbf{1}}=$ & $\mathbf{R}_{\mathbf{2}}=$ & solvent & $\begin{array}{l}\text { Time } \\
\text { (h) }\end{array}$ & $\begin{array}{l}\text { Method-A } \\
\text { Yield (\%) }\end{array}$ & $\begin{array}{l}\text { Method-B } \\
\text { Yield (\%) }\end{array}$ \\
\hline 1 & $\mathbf{1 a}$ & $\mathrm{H}$ & $\mathrm{H}$ & $\mathrm{H}$ & $\mathrm{CH}_{2} \mathrm{Cl}_{2}$ & 24 & 60 & 91 \\
\hline 2 & $\mathbf{1 a}$ & $\mathrm{H}$ & $\mathrm{H}$ & $\mathrm{H}$ & toluene & 36 & 57 & \\
\hline 3 & $\mathbf{1 a}$ & $\mathrm{H}$ & $\mathrm{H}$ & $\mathrm{H}$ & $\mathrm{CH}_{3} \mathrm{CN}$ & 72 & 41 & \\
\hline 4 & $\mathbf{1 a}$ & $\mathrm{H}$ & $\mathrm{H}$ & $\mathrm{H}$ & $\mathrm{CHCl}_{3}$ & 48 & 56 & \\
\hline 5 & $\mathbf{1 b}$ & $\mathrm{H}$ & $\mathrm{CH}$ & $\mathrm{H}$ & $\mathrm{CH}_{2} \mathrm{Cl}_{2}$ & 24 & 54 & 90 \\
\hline 6 & $\mathbf{1 c}$ & $\mathrm{H}$ & $\mathrm{C} 3 \mathrm{H}_{7}$ & $\mathrm{H}$ & $\mathrm{CH}_{2} \mathrm{Cl}_{2}$ & 24 & 56 & 88 \\
\hline 7 & $\mathbf{1 d}$ & $\mathrm{H}$ & $\mathrm{Ph}$ & $\mathrm{H}$ & $\mathrm{CH}_{2} \mathrm{Cl}_{2}$ & 24 & 58 & 76 \\
\hline 8 & $\mathbf{1 e}$ & $\mathrm{H}$ & $\mathrm{COOEt}$ & $\mathrm{H}$ & $\mathrm{CH}_{2} \mathrm{Cl}_{2}$ & 18 & 78 & 93 \\
\hline 9 & $\mathbf{1 f}$ & $\mathrm{CH}$ & $\mathrm{H}$ & $\mathrm{CH}_{3}$ & $\mathrm{CH}_{2} \mathrm{Cl}_{2}$ & 24 & 9 & 15 \\
\hline 10 & $\mathbf{1 g}$ & $\mathrm{Br}$ & $\mathrm{H}$ & $\mathrm{H}$ & $\mathrm{CH}_{2} \mathrm{Cl}_{2}$ & 48 & 5 & 12 \\
\hline 11 & $\mathbf{1 h}$ & $\mathrm{CH}$ & $\mathrm{CH}$ & $\mathrm{H}$ & $\mathrm{CH}_{2} \mathrm{Cl}_{2}$ & 72 & 0 & 0 \\
\hline 12 & $\mathbf{1 i}$ & $\mathrm{H}$ & $\mathrm{CH}$ & $\mathrm{CH}$ & $\mathrm{CH}_{2} \mathrm{Cl}_{2}$ & 72 & 0 & 0 \\
\hline
\end{tabular}

To test the generality of the procedure, various substates were subjected to the reaction conditions (see table 1) and it is concluded that the ease of reduction is sensitive to steric and electronic factor. For example, when cinnamoyl ester (entry 8, Method-A) high yield is obtained, due to two electron withdrawing group on either side. Whereas low chemical yield $(<10 \%)$ was obtained with $\alpha$-methyl (entry 9 , Method-A) or $\alpha$-bromo (entry 10, Method-A) substituent while no desired products were isolated when $\alpha, \beta-$ dimethyl (entry 11, Method-A) or $\beta, \beta$-dimethyl (entry 12, Method-A) substrates were used. Even more interestingly the chemical yields were significantly improved in the presence of catalytic amount of Lewis acid (entries 1 and 5-8, Method-B). In case of 
$\alpha, \beta$-dimethyl (entry 11, Method-B) or $\beta, \beta$-dimethyl (entry 12 , Method-B), even increase the catalyst load to $0.5 \%$ and prolong reaction time also did not gave the products. The used of triethylamine or DBU is ineffective on the rate of reaction.

To further explore the utility of O-mesityl(sulfonyl)hydroxylamine as a new and convenient entry to hydrogenation methods, a variety of $\alpha, \beta$-unsaturated carbonyl derivatives were studied, and the results are summarized in Table 2. The carbon carbon double bond in several structurally varied amides underwent hydrogenation to give the corresponding saturated analogues in moderate to excellent yields by this procedure. The substituents on the olefins apparently have influence on the course of hydrogenation. Other reducible groups such as ethyl ester or amide, halogen, nitro groups were fully compatible with the reaction conditions and remained unaltered. The mechanistic explanation of this reaction remained unclear and it is believed that self coupling of reagent occurs to form the diimide 27,28 compounds with liberation of hydrogen gas, which is consumed by olefins during reaction.

Table 2 Selective hydrogenation of various $\alpha, \beta$-unsaturated carbonyl derivatives using $\mathrm{O}$-mesityl(sulfonyl)hydroxylamine in the presence of $\mathrm{Yb}(\mathrm{OTf})_{3} .^{a}$

entry substrate

a The conjugated carbonyl compound $(1.0 \mathrm{mmol})$ was stirred with $O$ mesityl(sulfonyl)hydroxylamine $(10 \mathrm{mmol})$ and ytterbium triflate $(0.1 \mathrm{mmol})$ in $\mathrm{CH}_{2} \mathrm{Cl}_{2}(10$ $\mathrm{mL}$ ) at ambient temperature. ${ }^{b}$ Isolated yield. 
In separate experiments, the compounds with nitrile group and azide were treated under same reaction conditions, we recovered starting materials only, it further enhances the selective reduction of unsaturated carbonyl compounds over nitrile and azides.

The experimental procedure is very simple and straight forward. The conjugated carbonyl compound $(0.25-0.5 \mathrm{mmol})$ was stirred with O-mesityl(sulfonyl)hydroxylamine $(1-2 \mathrm{mmol})$ and ytterbium triflate $(0.025-0.05 \mathrm{mmol})$ in dichloromethane $(5-10 \mathrm{~mL})$ was stirred for a certain period of time as required to complete the reaction. (usually $24 \mathrm{~h}$ ). After completion of reaction, dilute with water, extract with dichloromethane. Wash the organic layer with water, brine, dried over $\mathrm{MgSO}_{4}$ and concentrated under reduced pressure to get the crude product, which on column chromatography purification gives pure product.in $60-93 \%$ yield.

In summary, the mild condition, high yields of products, operational simplicity, easy availability of reagent and no external use of explosive hydrogen gas makes this methodology a more useful and practical alternative to the existing methods for reduction of $\alpha, \beta$ - unsaturated carbonyl compounds. This extends the synthetic application to O-mesityl(sulfonyl)hydroxylamine. We believe that this method will find useful applications in the field of organic synthesis.

\section{- Acknowledgement}

G.S.R thankful to National Science Council of Taiwan, (ROC) for financial support in the form of Post-Doctoral Fellowship during February 2000-July 2003. G.S.R is thankful to Kwunmin Chen at National Taiwan Normal University, Taipei, Taiwan, for conducting the experiments and collection and processing of the spectral data and X-ray data are gratefully acknowledged.

- Competing interests: There is no Competing Interests pending

Data and materials availability: Crystallographic model data is available through the CCDC under identifier 1999014 [(6R,7aR)-8,8-dimethyl-2-phenyl-1-(3phenylpropanoyl)hexahydro-3a,6-methanoindazol-3(2H)-one, 2d]. 1990770 [(6R,7aR)1-(2-bromopropanoyl)-8,8-dimethyl-2-phenylhexahydro-3a,6-methanoindazol-3(2H)one, 2g],

\section{Reference}

1 Bigge, C. F. et al. Exploration of N-phosphonoalkyl-, N-phosphonoalkenyl-, and N(phosphonoalkyl)phenyl-spaced .alpha.-amino acids as competitive N-methyl-D-aspartic 
acid antagonists. Journal of Medicinal Chemistry 35, 1371-1384, doi:10.1021/jm00086a005 (1992).

2 Francis, J. E. et al. Highly selective adenosine A2 receptor agonists in a series of Nalkylated 2-aminoadenosines. Journal of Medicinal Chemistry 34, 2570-2579, doi:10.1021/jm00112a035 (1991).

3 Paryzek, Z., Koenig, H. \& Tabaczka, B. Ammonium Formate/Palladium on Carbon: A Versatile System for Catalytic Hydrogen Transfer Reductions of Carbon-Carbon Double Bonds. Synthesis 2003, 2023-2026, doi:10.1055/s-2003-41024 (2003).

4 Berthold, H., Schotten, T. \& Hönig, H. Transfer Hydrogenation in Ionic Liquids under Microwave Irradiation. Synthesis 2002, 1607-1610, doi:10.1055/s-2002-33349 (2002).

5 Mori, A. et al. Pd/C-Catalyzed Chemoselective Hydrogenation in the Presence of Diphenylsulfide. Organic Letters 8, 3279-3281, doi:10.1021/o1061147j (2006).

6 Park, C. M., Kwon, M. S. \& Park, J. Palladium Nanoparticles in Polymers: Catalyst for Alkene Hydrogenation, Carbon-Carbon Cross-Coupling Reactions, and Aerobic Alcohol Oxidation. Synthesis 2006, 3790-3794, doi:10.1055/s-2006-950329 (2006).

7 Arcadi, A., Bernocchi, E., Cacchi, S. \& Marinelli, F. Palladium-Catalyzed Conjugate Reduction of $\alpha, \beta$-Unsaturated Carbonyl Compounds with Potassium Formate. Synlett 1991, 27-28, doi:10.1055/s-1991-20615 (1991).

8 Brunel, J. M. Pd/P(t-Bu)3: A Mild Catalyst for Selective Reduction of Alkenes under -Transfer-Hydrogenation Conditions. Synlett 2007, 0330-0332, doi:10.1055/s-2007968005 (2007).

9 Yamashita, M., Tanaka, Y., Arita, A. \& Nishida, M. Organic reactions using sodium hydrogentelluride. 3. The Reaction of Sodium Hydrogentelluride with .alpha.,.beta.Unsaturated Carbonyl Compounds. The Journal of Organic Chemistry 59, 3500-3502, doi:10.1021/jo00091a050 (1994).

10 Mendes-Burak, J., Ghaffari, B. \& Copéret, C. Selective hydrogenation of $\alpha, \beta$-unsaturated carbonyl compounds on silica-supported copper nanoparticles. Chemical Communications 55, 179-181, doi:10.1039/C8CC08457B (2019).

11 Yanada, R., Bessho, K. \& Yanada, K. Metallic Samarium and Iodine in Alcohol. Selective 1,4-Reduction of $\alpha, \beta$-Unsaturated Carboxylic Acid Derivatives. Synlett 1995, 443-444, doi:10.1055/s-1995-5000 (1995).

12 Sayama, S. \& Inamura, Y. Conjugate Reduction of 2-Butene-1,4-diones with LiAlH4$\mathrm{SbCl3}$. Bulletin of the Chemical Society of Japan 64, 306-308, doi:10.1246/bcsj.64.306 (1991).

13 Bartoli, G., Cimarelli, C., Marcantoni, E., Palmieri, G. \& Petrini, M. Chemo- and Diastereoselective Reduction of .beta.-Enamino Esters: A Convenient Synthesis of Both cis- and trans-.gamma.-Amino Alcohols and .beta.-Amino Esters. The Journal of Organic Chemistry 59, 5328-5335, doi:10.1021/jo00097a039 (1994).

14 Dalla, V., Cotelle, P. \& Catteau, J. P. Chemocontrolled reduction of aromatic $\alpha-$ ketoesters by NaBH4: Selective synthesis of $\alpha$-hydroxy esters or 1,2-diols. Tetrahedron Letters 38, 1577-1580, doi:https://doi.org/10.1016/S0040-4039(97)00154-8 (1997).

15 Alonso, F., Osante, I. \& Yus, M. Conjugate Reduction of $\alpha, \beta$-Unsaturated Carbonyl Compounds Promoted by Nickel Nanoparticles. Synlett 2006, 3017-3020, doi:10.1055/s2006-951494 (2006).

16 Guo, S. \& Zhou, J. N,N-Dimethylformamide as Hydride Source in Nickel-Catalyzed Asymmetric Hydrogenation of $\alpha, \beta$-Unsaturated Esters. Organic Letters 18, 5344-5347, doi:10.1021/acs.orglett.6b02662 (2016).

17 Zhang, D., Iwai, T. \& Sawamura, M. Iridium-Catalyzed Alkene-Selective Transfer Hydrogenation with 1,4-Dioxane as Hydrogen Donor. Organic Letters 21, 5867-5872, doi:10.1021/acs.orglett.9b01989 (2019).

18 Cheng, X., Zhang, Q., Xie, J.-H., Wang, L.-X. \& Zhou, Q.-L. Highly Rigid Diphosphane Ligands with a Large Dihedral Angle Based on a Chiral Spirobifluorene Backbone. 
Angewandte Chemie International Edition 44, 1118-1121, doi:10.1002/anie.200462072 (2005).

19 Itoh, K., Tsuruta, A., Ito, J.-i., Yamamoto, Y. \& Nishiyama, H. Enantioselective Synthesis of Optically Active 3,3-Diarylpropanoates by Conjugate Hydrosilylation with Chiral Rh-bis(oxazolinyl)phenyl Catalysts. The Journal of Organic Chemistry 77, 1091410919, doi:10.1021/jo302357b (2012).

20 Bak, R. R., McAnda, A. F., Smallridge, A. J. \& Trewhella, M. A. The Yeast-Mediated Reduction of Nitrostyrenes in Organic Solvent Systems. Australian Journal of Chemistry 49, 1257-1260 (1996).

21 Jat, J. L. et al. Direct Stereospecific Synthesis of Unprotected N-H and N-Me Aziridines from Olefins. Science 343, 61, doi:10.1126/science.1245727 (2014).

22 Haga, N., Endo, Y., Kataoka, K., Yamaguchi, K. \& Shudo, K. Acid-catalyzed aminomigration of O-phenylhydroxylamines. Journal of the American Chemical Society 114, 9795-9806, doi:10.1021/ja00051a012 (1992).

23 Tamura, Y., Sumoto, K., Matsushima, H., Taniguchi, H. \& Ikeda, M. Reactions of Nsubstituted arylsulfilimines with acylating agents and with activated halobenzenes, alkynes, and alkenes. The Journal of Organic Chemistry 38, 4324-4328, doi:10.1021/jo00964a025 (1973).

24 Yamawaki, K. et al. A novel series of parenteral cephalosporins exhibiting potent activities against Pseudomonas aeruginosa and other Gram-negative pathogens: Synthesis and structure-activity relationships. Bioorganic \& Medicinal Chemistry 15, 6716-6732, doi:https://doi.org/10.1016/j.bmc.2007.08.001 (2007).

25 Tang, Y., Kumar, D. \& Shreeve, J. n. M. Balancing Excellent Performance and High Thermal Stability in a Dinitropyrazole Fused 1,2,3,4-Tetrazine. Journal of the American Chemical Society 139, 13684-13687, doi:10.1021/jacs.7b08789 (2017).

26 Chandra, D. et al. Direct synthesis of secondary amides from ketones through Beckmann rearrangement using O-(mesitylsulfonyl)hydroxylamine. Tetrahedron Letters, 151822, doi:https://doi.org/10.1016/j.tetlet.2020.151822 (2020).

27 Brandemark, U. \& Siegbahn, P. E. M. Dissociation of diimide. Theoretica chimica acta 66, 217-232, doi:10.1007/BF00549671 (1984).

28 Lacombe, P., Castagner, B., Gareau, Y. \& Ruel, R. Reduction of olefins on solid support using diimide. Tetrahedron Letters 39, 6785-6786, doi:https://doi.org/10.1016/S00404039(98)01490-7 (1998). 